\title{
Estrogen is neuroprotective against hypoglycemic injury in murine N38 hypothalamic cells
}

\author{
TANDRA R. CHAKRABORTY ${ }^{1}$, JOSHUA COHEN ${ }^{1}$, DARIEN YOHANAN ${ }^{1}$, \\ EILLIUT ALICEA ${ }^{1}$, BENJAMIN S. WEEKS ${ }^{1,2}$ and SANJOY CHAKRABORTY ${ }^{3}$ \\ Departments of ${ }^{1}$ Biology and ${ }^{2}$ Environmental Studies Program, Adelphi University, Garden City, NY 11530; \\ ${ }^{3}$ Department of Biological Sciences, New York City College of Technology, \\ City University of New York, New York, NY 11201, USA
}

Received April 28, 2016; Accepted August 25, 2016

DOI: $10.3892 / \mathrm{mmr} .2016 .5952$

\begin{abstract}
Estrogen (E2) has been demonstrated to possess protective effects from hypoglycemic toxicity, particularly in the pancreas. In the central nervous system, several brain regions, such as the hypothalamus, are highly vulnerable to hypoglycemic injuries that may lead to seizures, coma, and mortality. The present study performed a novel in vitro assay of hypoglycemic injury to hypothalamic cells, and is the first study, to the best of our knowledge, to demonstrate that E2 protects hypothalamic cells from hypoglycemic toxicity. The toxic effects of hypoglycemia on hypothalamic cells in vitro was determined by performing cell counts, together with MTT and lactate dehydrogenase assays, using the N38 murine hypothalamic cell line. Following 24 and $48 \mathrm{~h}$ in hypoglycemic conditions, a 60 and $75 \%$ reduction in cell number and mitochondrial function was observed, which reached 80 and $\sim 100 \%$ by 72 and 96 h, respectively. E2 treatment prevented the hypoglycemia-induced loss in cell number and mitochondrial toxicity at 24 and $48 \mathrm{~h}$. However at 72 and $96 \mathrm{~h}$ of hypoglycemic conditions, the neuroprotective effects of E2 on cell number or mitochondrial function was not significant or not present at all. In order to determine whether E2 exerted its effects through the AKT signaling pathway, the expression of proline-rich AKT substrate of $40 \mathrm{kDa}$ (PRAS40) was analyzed. No alterations in PRAS40 expression were observed when N38 cells were exposed to hypoglycemic shock. From the biochemical and molecular data obtained, the authors speculated that E2 exhibits neuroprotective effects against hypoglycemic shock in hypothalamic cells, which dissipates with time. Despite demonstrating no significant effect on total AKT/PRS40 activity, it is possible that E2 may mediate
\end{abstract}

Correspondence to: Dr Tandra R. Chakraborty, Department of Biology, Adelphi University, 1 South Avenue, Garden City, NY 11530, USA

E-mail: chakraborty@adelphi.edu

Key words: AKT, estrogen, hypothalamus, neuroprotection, proline-rich AKT substrate of $40 \mathrm{kDa}$ these neuroprotective effects by upregulating the phosphorylated-AKT/pPRAS40 signaling pathway. The present study presented, to the best of our knowledge, the first in vitro model for hypoglycemic toxicity to hypothalamic cells, and provided evidence to suggest that E2 may protect hypothalamic cells from the damaging effects of hypoglycemia.

\section{Introduction}

Glucose is the primary metabolic fuel of the brain, and its availability is directly associated with neuronal activity (1). Recurrent episodes of hypoglycemia; a condition where blood glucose level decrease to below normal levels as a result of the administration of an incorrect insulin dosage, prolonged fasting or strenuous exercise, may result in the loss of neurons, impaired intelligence quotient and may ultimately lead to morbidity (2). Hernandez-Fonseca et al (3) demonstrated that the cerebral cortex and hippocampus, which are critically important for cognition, are vulnerable to injury as a result of hypoglycemia. Very little is known about the effects of hypoglycemia on the function of the hypothalamus, which is a region of the brain that is critically important for regulating feeding and energy balance, and is rich in glucose-sensing neurons (4).

Previously, ovarian steroid hormones have been demonstrated to exhibit important effects in the maintenance of brain function (5). Estrogen (E2) has been demonstrated to possess anti-apoptotic effects $(6,7)$, and neuroprotective effects against stroke (ischemic injury) (8), memory-associated behavioral tasks (9) and hypertension (10). Postmenopausal women taking hormone replacement therapy demonstrate a reduction in counter-regulatory responses to hypoglycemia when compared with women not taking E2 (11). The actions of E2 are mediated through: i) The increased synthesis and activity of growth factors (12); ii) a reduction in the activity of apoptotic factors (13); iii) protection from several neurotoxic agents (14-16); iv) potential antioxidant effects, leading to a reduction in neuronal nitric oxide synthase in brain homogenates (6); and iv) a reduction in glutamate receptors (17).

A number of previous studies have reported the neurotrophic and neuroprotective effects of E2 (6,16,18-20). For instance, E2 has been demonstrated to stimulate the growth 
of hypothalamic explants, as well as those in the preoptic area of the basal diencephalons (18). In addition, E2 protects neuroblastoma cells from serum deprivation (19), increases the mRNA expression levels of the gene encoding the anti-apoptotic NEP1-interacting protein in neuroblastoma (16), completely attenuates hemoglobin neurotoxicity in cortical cultures (20), and protects primary cerebrocortical neurons from hypoglycemia (6).

It has been suggested that E2 affects cell viability, survival and proliferation, and regulates the expression of target genes through two mechanisms: i) By binding to and activating the estrogen receptor (ER)- $\alpha$ and ER- $\beta$ receptors, which belong to the steroid/thyroid hormone superfamily of transcription factors $(21,22)$, and are responsible for mediating the classical or genomic pathways of E2 to regulate gene transcription; and ii) by mediating intracellular signaling of membrane receptors [e.g. G-protein, $\mathrm{Ca}^{2+}$, cyclic adenosine monophosphate (cAMP) and protein kinase C] $(23,24)$, which are located in the cytoplasm or the plasma membrane and are involved in the non-genomic or membrane-initiated steroid signaling pathways of E2.

Survival stimuli generally activate transmembrane receptors through $\mathrm{G}$-protein coupled receptors located in the plasma membrane $(25,26)$. As a result, phosphotidylinositol-3-OH kinase (PI3K) is activated, which subsequently activates a cascade of signaling molecules leading to alterations in the AKT/protein kinase B signaling pathway (27); a key regulator of neuronal cell death. AKT is a proto-oncogene, which is activated by a variety of substrates and has numerous effects, including regulating cell survival, proliferation and protein synthesis. The first step in the AKT pathway is the activation of the receptor tyrosine kinase (RTK). RTK activates PI3K, which phosphorylates phosphatidylinositol phosphate (PIP)-2 to PIP3. PIP3 then phosphorylates and activates AKT (28) at threonine 308 and serine 473 residues. Transfection of granule cells with a dominant-negative AKT allele abolished the ability of insulin-like growth factor-1 to promote cell survival (29). By contrast, transfecting granule cells with wild-type AKT alleles promoted cell survival (29). A previous study suggested that AKT inhibits apoptosis induced by death stimuli, and its activity is required for growth factor-induced survival (30). PRAS40 is a substrate of AKT, and due to this functional association, PRAS40 expression is considered to be a marker of AKT activity. PRAS40 is phosphorylated by AKT and binds to 14-3-3 family proteins $(30,31)$.

While a number of in vitro and in vivo models exist to study the toxicity of hypoglycemia and investigate the protective effects of E2 $(7,32)$ to the best of our knowledge, the present study is the first to report hypoglycemic damage to hypothalamic cells and demonstrate that E2 protects hypothalamic cells from hypoglycemic conditions. Using this system, E2 was observed to protect hypothalamic cells from hypoglycemic shock. The authors hypothesize that the neuroprotective effects of E2 under hypoglycemic conditions may be mediated through the AKT signaling pathway.

\section{Materials and methods}

Cell culture and glucopenic insult. The N38 murine hypothalamic cell line (Cedarlane, Cellutions Biosystems, Burlington,
Ontario, Canada) was cultured in Dulbecco's modified Eagle's medium (DMEM, consisting of $4.5 \mathrm{~g} / 1$ glucose, L-glutamine, sodium pyruvate and phenol red; 1X; Mediatech; Corning Life Sciences, Corning, NY, USA) containing $0.5 \%$ fetal bovine serum (FBS, Mediatech; Corning Life Sciences) and 1\% penicillin-streptomycin (Mediatech; Corning Life Sciences) until the cells reached $70 \%$ confluence. N38 cells were subsequently washed with DMEM, trypsinized with trypsin EDTA (1X; Mediatech; Corning Life Sciences) and divided into the following groups based on different media formulations: i) DMEM group, consisting of DMEM plus $0.5 \% \mathrm{FBS}$; ii) DMEM-G group, cultured in DMEM (1X; Gibco; Thermo Fisher Scientific, Inc., Waltham, MA, USA) with sodium pyruvate plus $5 \%$ FBS in the absence of glucose; iii) DMEM-PR group, cultured in DMEM (1X; Mediatech; Corning Life Sciences) with sodium pyruvate plus glucose and 5\% FBS in the absence of phenol red; iv) DMEM+E2 group, cultured in DMEM plus $1 \mathrm{mM}$ E2 (beta-estradiol; Sigma-Aldrich; Merck Millipore, Darmstadt, Germany) and 5\% FBS; v) DMEM-G+E2 group, cultured in DMEM plus $1 \mathrm{mM}$ E2 and $5 \%$ FBS in the absence of glucose; and vi) DMEM-PR+E2 group, cultured in DMEM in absence of phenol red, with $1 \mathrm{mM}$ E2 and 5\% FBS. These media formulations were selected in order to assess cell growth and proliferation under the following conditions: i) normal; ii) hypoglycemic; iii) in the absence of phenol red, as phenol red is known to exhibit mild estrogenic effects, but is commonly used as an indicator of $\mathrm{pH}$ in cell growth medium (33); iv) in the presence of estrogen only; v) in hypoglycemic conditions plus estrogen; vi) in the absence of phenol red and the presence of estrogen.

Assessment of cell morphology and number. Cells were cultured in 6 -well plates $\left(\sim 1 \times 10^{4}-1 \times 10^{5}\right.$ cells/well $)$ and maintained in the different media formulations for 24, 48, 72 and $96 \mathrm{~h}$ at $37^{\circ} \mathrm{C}$ and a relative humidity of $95 \%$. At each time point, the cells were trypsinized and counted with a hemocytometer. Under the microscope N38 cells were oval-shaped cell bodies connected to extensions. Rounded cells with no extensions were considered to be dead. Preliminary experiments were conducted using trypan blue in order to determine the viability of cells. Photomicrographs of cells cultured in DMEM, DMEM without glucose and DMEM plus $1 \mathrm{mM} \mathrm{E2}$ in the absence of glucose at 24 and $72 \mathrm{~h}$ were obtained in order to detect morphological changes in the cells.

Assessment of mitochondrial activity using the 3-(4,5-dime thyl-2-thiazolyl)-2,5-diphrenyltetrazolium bromide (MTT) assay. The MTT assay provides a quantitative measure of mitochondrial activity and is an indicator of cell viability. The assay is based on the conversion of a tetrazolium salt to the colored product formazan by dehydrogenase enzymes, which can be detected spectrophotometrically (34). Under glucopenic stress, cells may exhibit altered mitochondrial activity, which can be detected using the MTT assay. For the purposes of the present study, cell viability was assessed using the MTT Cell Proliferation assay kit (cat. no. 30-1010K; American Type Culture Collection, Manassas, VA, USA) according to the manufacturer's instructions. N38 cells were cultured in 6-well plates (10,000 cells/well) and maintained in the different media formulations for 24, 48, 72 and $96 \mathrm{~h}$ before 

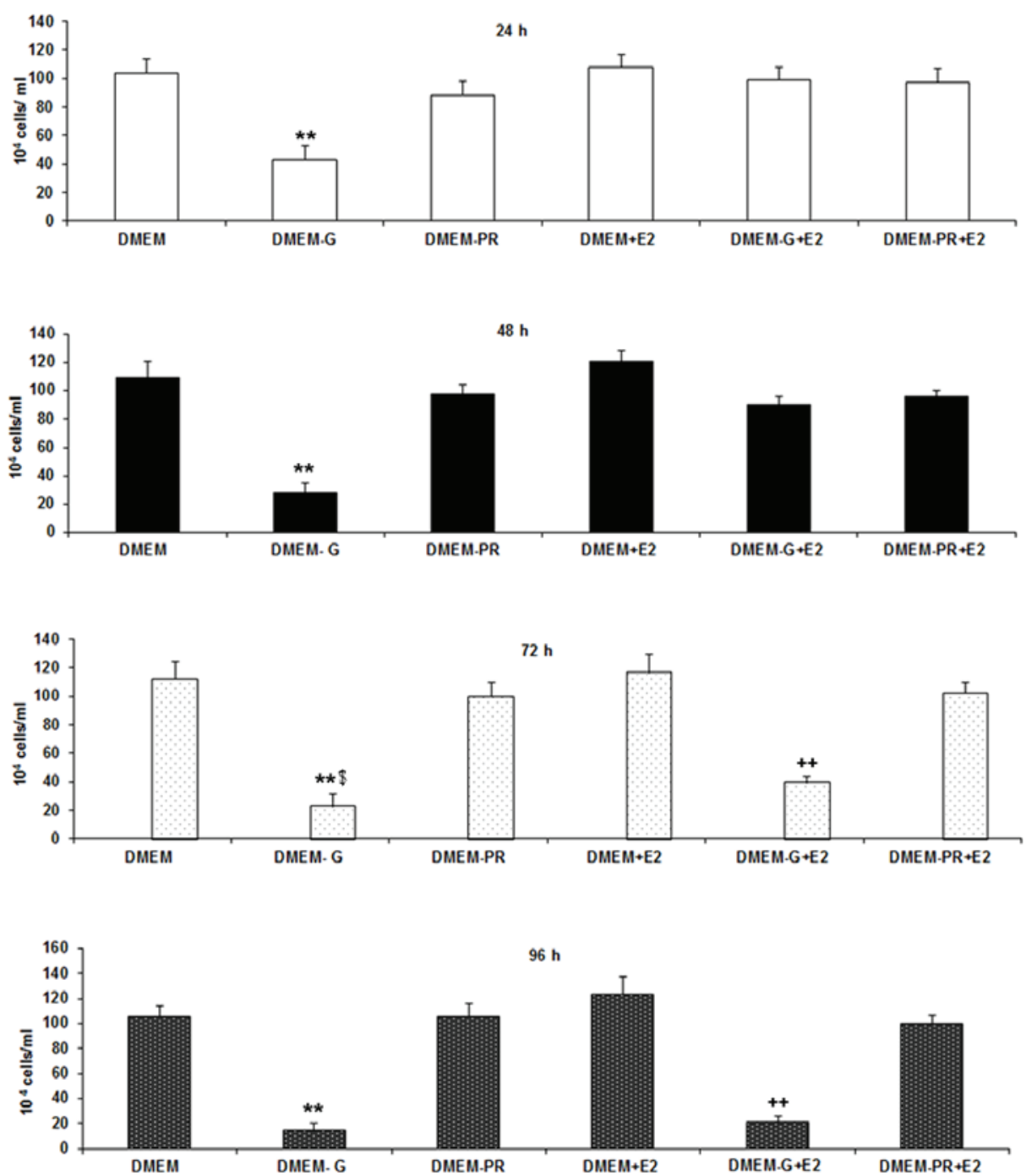

Figure 1. N38 cell numbers cultured in different media formulations for 24, 48, 72 and 96 h. Cells cultured in DMEM, DMEM+E2 and DMEM-PR demonstrated no significant alterations in cell number across all time points. Cells in the DMEM-G group exhibited a significant reduction in cell number within $24 \mathrm{~h}$ when compared with the other experimental groups. At $48 \mathrm{~h}$, the effect was similar when compared with the $24 \mathrm{~h}$ time-point. The significance level gradually decreased when exposed to hypoglycemic conditions in the presence of estrogen (DMEM-G+E2) at 72 and $96 \mathrm{~h}$ when compared to the DMEM-G group. ${ }^{* *} \mathrm{P}<0.0001$ vs. other groups at all time points (except DMEM-G+E2 at 72 and $96 \mathrm{~h}$ ); ${ }^{\$} \mathrm{P}<0.05$ vs. DMEM-G+E2 at $72 \mathrm{~h} ;{ }^{++} \mathrm{P}<0.0001$ vs. all groups at all time points (except DMEM-G at 72 and 96 h). DMEM; Dulbecco's modified Eagle's medium plus phenol red; DMEM-G, DMEM without glucose; DMEM-PR, DMEM without phenol red; DMEM+E2, DMEM plus $1 \mathrm{mM}$ estrogen; DMEM-G+E2, DMEM plus $1 \mathrm{mM}$ E2 without glucose; DMEM-PR+E2, DMEM plus $1 \mathrm{mM}$ E2 without phenol red.

MTT reagent was added. The absorbance was read at $570 \mathrm{~nm}$. Since, no significant alterations in cell viability were observed at 48 and $96 \mathrm{~h}$, cells cultured for 24 and $72 \mathrm{~h}$ were used for further analyses.

Assessment of cell injury by lactate dehydrogenase ( $L D H)$ activity. Cell injury was assessed using the Cytotoxicity Detection kit ${ }^{\text {PLUS }}$ (LDH; cat. no. 04744926 001, Roche Diagnostics, Indianapolis, IN, USA), which measures LDH activity released from cells with damaged plasma membranes, according to the methods described previously by Regan and Panter (35). Briefly, the cells were cultured in 6-well plates $\left(1 \times 10^{6} \mathrm{cells} / \mathrm{ml} / \mathrm{well}\right)$ and in the different media formulations for 24 and $72 \mathrm{~h}$. For each experimental condition one well was designated as a high control (maximum LDH activity produced in cells=maximum LDH release) and one as a low control (LDH activity produced by untreated normal cells $=$ spontaneous LDH release). Prior to the addition of lysis buffer to the high control all cells were incubated for $\sim 15 \mathrm{~min}$ at $37^{\circ} \mathrm{C}, 5 \% \mathrm{CO}_{2}$ and $95 \%$ humidity. A mixture of catalyst and dye was then added to each of the wells and incubated for $20 \mathrm{~min}$ at $25^{\circ} \mathrm{C}$ in the dark, before the stop solution was added. The optical density (OD) was determined at $490 \mathrm{~nm}$ and the level of cytotoxicity was calculated using the following formula: Cytotoxicity $(\%)=[($ sample OD-low control OD)/(high control OD-low control OD)]x100.

Assessment of the non-genomic pathway of neuroprotection by E2 using a PRAS40 enzyme-linked immunosorbent assay (ELISA). N38 cells were first exposed to glucopenic stress for $24 \mathrm{~h}$, using the aforementioned methods. As the neuroprotective effect of E2 was most pronounced at $24 \mathrm{~h}$, the mechanism 

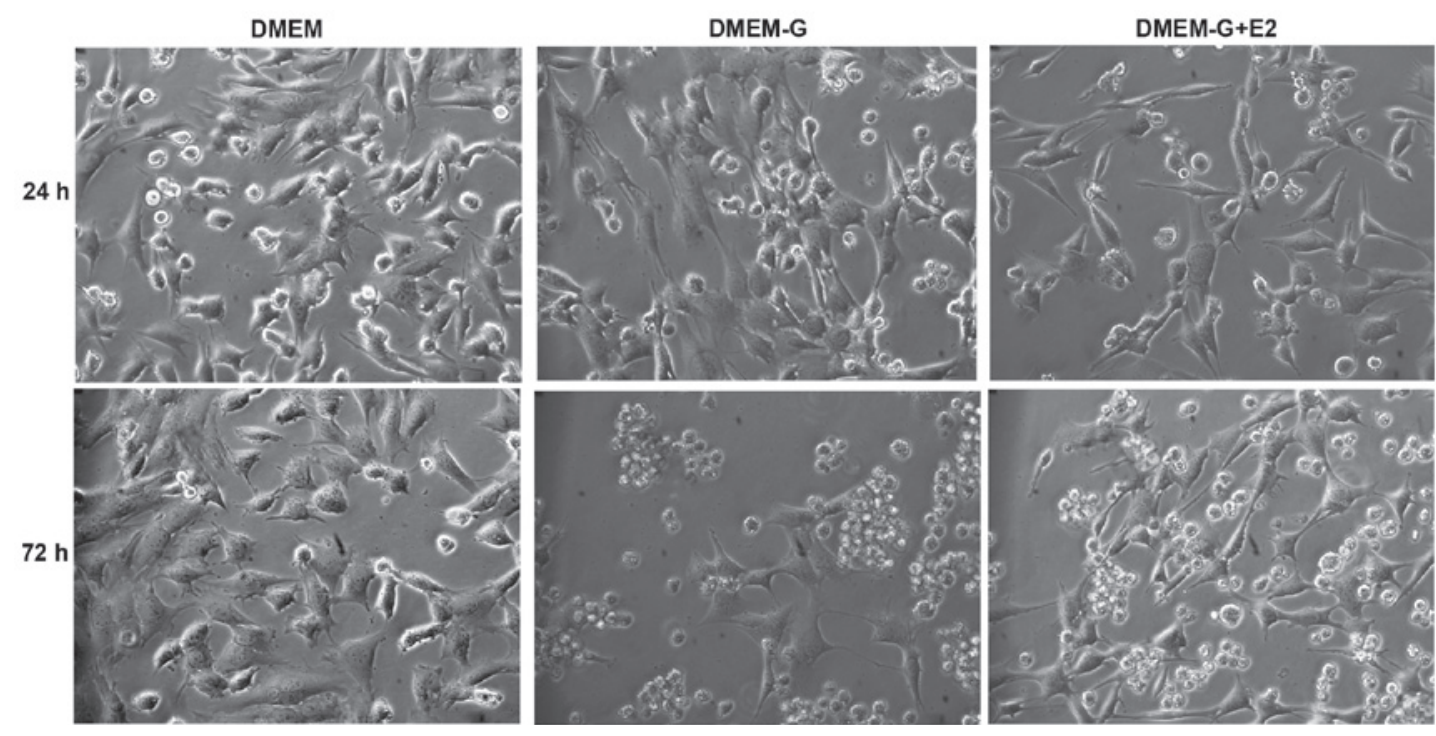

Figure 2. Qualitative analysis of N38 cell number in DMEM, DMEM-G and DMEM-G+E2 groups at 24 and $72 \mathrm{~h}$ (magnification, x32). In the absence of glucose a marked increase in the number of non-viable cells (rounded cells with no extensions) was observed at 24 and $72 \mathrm{~h}$ compared with cells in DMEM. In the presence of E2, the number of non-viable cells in the DMEM-G+E2 decreased when compared with the DMEM-G group at $24 \mathrm{~h}$. A greater number of non-viable cells was observed in the DMEM-G and DMEM-G+E2 groups at $72 \mathrm{~h}$ compared with $24 \mathrm{~h}$. DMEM; Dulbecco's modified Eagle's medium plus phenol red; DMEM-G, DMEM without glucose; DMEM-G+E2, DMEM plus $1 \mathrm{mM}$ estrogen without glucose.

of action of E2 was studied only at that time point. Using the PRAS40 STAR ELISA kit (cat. no. 17-477; EMD Millipore, Billerica, MA, USA), the cells were treated according to the manufacturer's protocol and the supernatants were extracted. Using the anti-PRAS40 antibody (cat. no. 17-477B) and the horseradish peroxidase-conjugated anti-rabbit immunoglobulin G secondary antibody (cat. no. 17-477E) included in the ELISA kit, PRAS40 expression was detected, according to the manufacturer's protocol.

Statistical analysis. The data obtained from the cell count, MTT, LDH and PRAS40 ELISA assays were expressed as the mean \pm standard deviation. Statistical differences among groups were analyzed using one-way analysis of variance with a post-hoc Tukey test (JMP software, version 7; SAS Institute, Inc., Cary, NC, USA). $\mathrm{P}<0.05$ was considered to indicate a statistically significant difference.

\section{Results}

Microscopic and quantitative analysis of the neuroprotective effects of E2 on cell survival following hypoglycemic injury. $\mathrm{N} 38$ cells in different groups were cultured in their respective media formulations for 24, 48, 72 and $96 \mathrm{~h}$ prior to visualization under a light microscope. As shown in Figs. 1 and 2, a qualitative and quantitative decrease in cell number under hypoglycemic conditions was observed. A significant increase in cell number was observed following exposure to E2 under hypoglycemic conditions at $24 \mathrm{~h}$ when compared with untreated cells under hypoglycemic conditions $\left(42.8 \times 10^{4}\right.$ vs. $98.5 \times 10^{4}$ cells; $\left.\mathrm{P}<0.0001\right)$. Within $72 \mathrm{~h}$ the effect dissipated and there was no significant difference in in cell number between cells exposed to hypoglycemic conditions in presence or absence of E2. The optimum concentration of E2 on reversing the effects of hypoglycemia in N38 cells was determined in preliminary experiments, by testing three different concentrations $(0.1,1$ and $10 \mathrm{mM})$ of E2 (data not shown). At $0.1 \mathrm{mM}$ E2 the number of cells was significantly lower compared with $1 \mathrm{mM}$ E2 $(\mathrm{P}=0.0096)$, and a 10 -fold increase in the concentration of E2 did not have any significant effect on cell number (data not shown). Therefore, the optimum concentration of E2 used in the present study was $1 \mathrm{mM}$. Cells in the DMEM-PR group exhibited no significant alterations in cell number when compared with cells in the DMEM group at all time points, which indicated that phenol red had no effect on cell number. No additive effects were observed following exposure of cells to DMEM+E2 when compared with cells exposed to DMEM-PR+E2 at all-time points (Fig. 1). The small decrease in cell number observed between cells exposed to DMEM-PR+E2 and DMEM+E2 did not reach statistical significance, which suggests that phenol red demonstrated no significant effect on the experimental results.

Assessing the effects of E2 on mitochondrial function in N38 cells under hypoglycemic conditions. Mitochondrial function was used to assess the viability of cells in each treatment group, as shown in Fig. 3. At 24 h, a significant reduction in mitochondrial function was observed in cells that were exposed to hypoglycemic conditions when compared with cells cultured in control media (DMEM vs. DMEM-G, $\mathrm{P}<0.0001)$. By contrast, a $\sim 80 \%$ increase in mitochondrial function was observed in cells in the presence of E2 under hypoglycemic conditions when compared with cells exposed to hypoglycemic conditions alone (DMEM-G vs. DMEM-G+E2, $\mathrm{P}<0.0001)$. The neuroprotective effects of E2 were gradually lost within $72 \mathrm{~h}$ of treatment, and cells exhibited a reduction in mitochondrial function even in the presence of E2 (Fig. 3, $\mathrm{P}<0.0001)$. However, the restoration of mitochondrial function by E2 did not prevent cell death but may have prolonged cellular survival, since mitochondrial function and cell viability were observed to decrease gradually over time in the presence of E2. A small population of cells was able to survive 

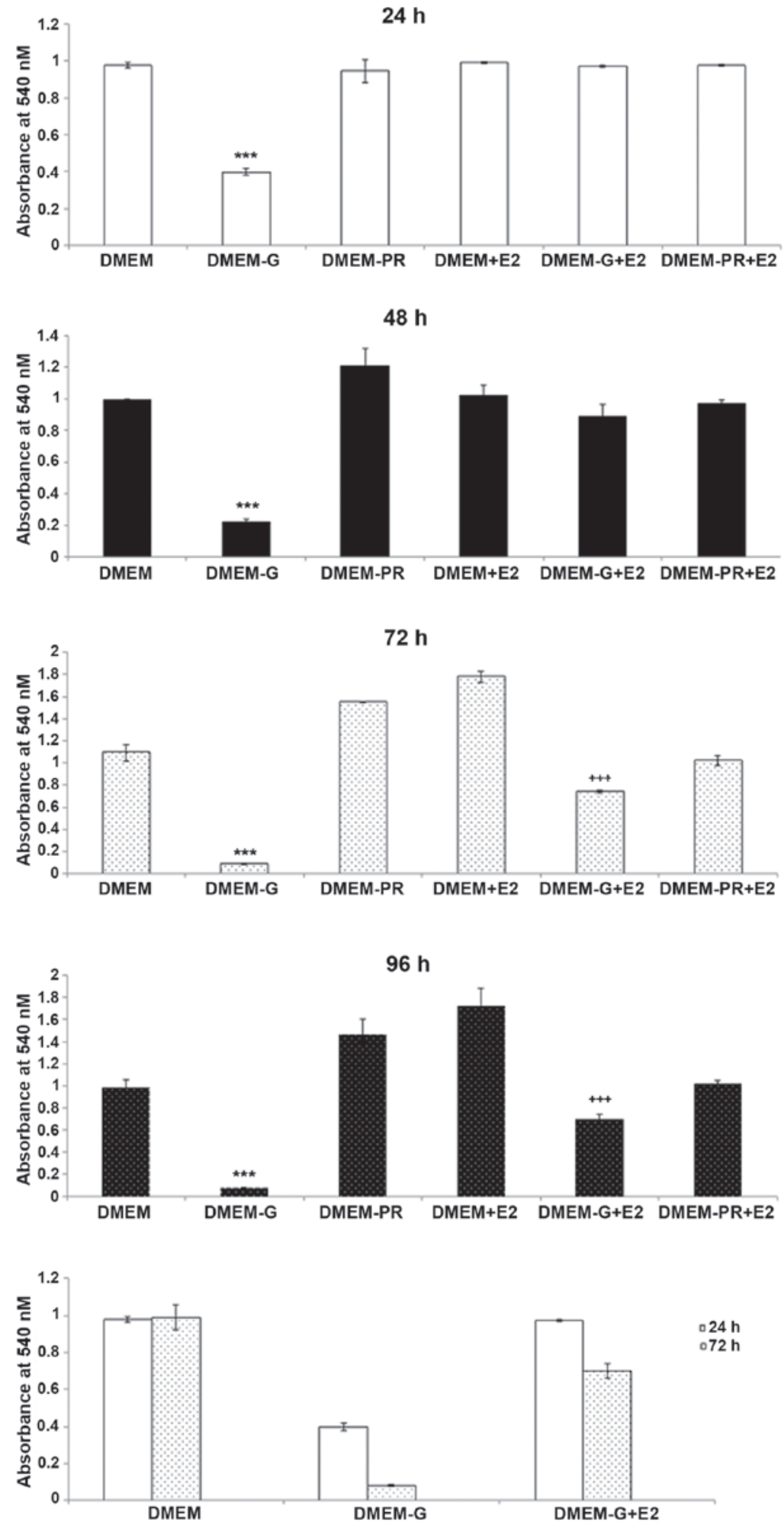

Figure 3. Mitochondrial function in N38 cells. The mitochondrial function of N38 cells under hypoglycemic conditions following exposure to E2 at 24, 48, 72 and $96 \mathrm{~h}$ was determined using the 3-(4,5-dimethyl-2-thiazolyl)-2,5-diphrenyltetrazolium bromide assay. Minimal mitochondrial function was observed in the DMEM-G group, which resulted in extensive cell death when compared with the other experimental groups at all time points (DMEM-G vs. DMEM, DMEM-PR, DMEM+E2, DMEM-G+E2, DMEM-PR+E2). Exposure to E2 demonstrated the highest mitochondrial function at $24 \mathrm{~h}(\mathrm{P}<0.0001)$. Exposure of cells under hypoglycemic conditions to E2 demonstrated a significant increase in mitochondrial function when compared with untreated cells under hypoglycemic conditions at $24 \mathrm{~h}$. The effect was similar at $48 \mathrm{~h}$. However, within $72 \mathrm{~h}$, a significant reduction in mitochondrial function was observed in DMEM-G+E2 cells when compared with DMEM-G cells. A similar effect was observed at $96 \mathrm{~h} .{ }^{* * * *} \mathrm{P}<0.0001 \mathrm{vs}$. all other groups at all time points; ${ }^{+++} \mathrm{P}<0.0001$ vs. all other groups at all time points. DMEM; Dulbecco's modified Eagle's medium plus phenol red; DMEM-G, DMEM without glucose; DMEM-PR, DMEM without phenol red; DMEM+E2, DMEM plus 1 mM estrogen; DMEM-G+E2, DMEM plus 1 mM E2 without glucose; DMEM-PR+E2, DMEM plus 1 mM E2 without phenol red.

in the absence of glucose for $72 \mathrm{~h}$ (Fig. 3). A gradual decrease in cell viability in the majority of experimental conditions was observed, likely due to the gradual depletion of growth factors in the media. Similar to E2-treated cells under hypoglycemic 
$24 \mathrm{~h}$

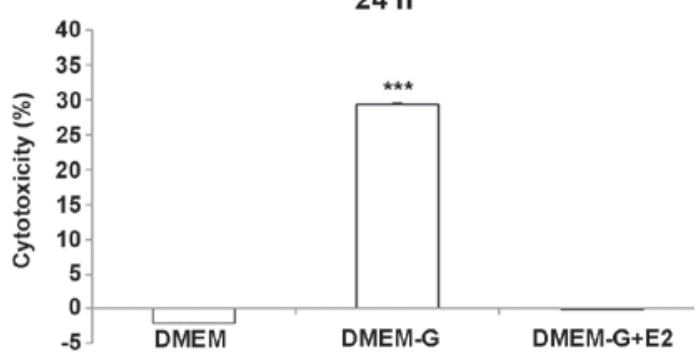

$72 \mathrm{~h}$

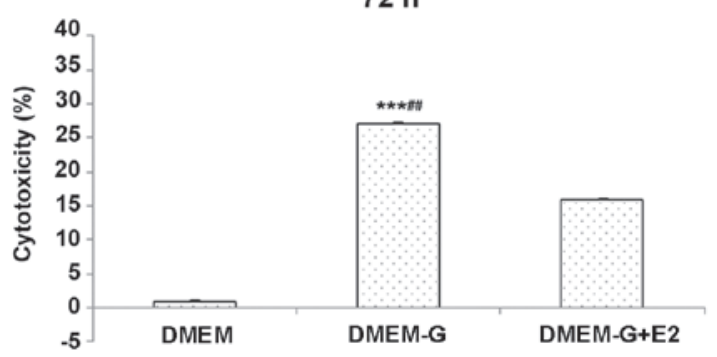

Figure 4. Effect of E2 on hypoglycemia-induced cytotoxicity in N38 cells. The effect of E2 on hypoglycemia-induced cytotoxicity in N38 cells at 24 and 72 h as determined using a lactate dehydrogenase assay. Negative values indicate no toxicity in cells. At $24 \mathrm{~h}$, a marked decrease in cytotoxicity was observed in cells under hypoglycemic conditions in and the presence of $1 \mathrm{mM} \mathrm{E2} \mathrm{compared} \mathrm{with} \mathrm{untreated} \mathrm{cells} \mathrm{under} \mathrm{hypoglycemic} \mathrm{conditions.} \mathrm{A} \mathrm{similar} \mathrm{effect} \mathrm{was} \mathrm{observed}$ when cells were cultured in DMEM, which indicates that E2 exhibits neuroprotective effects against cytotoxicity $(\mathrm{P}<0.0001)$. However, the level of cytotoxicity was significantly higher in cells exposed to $\mathrm{E} 2$ at $72 \mathrm{~h}$ compared with those at $24 \mathrm{~h} .{ }^{* * *} \mathrm{P}<0.0001$ vs. DMEM; ${ }^{\# \#} \mathrm{P}<0.01 \mathrm{vs}$. DMEM-G+E2. Dulbecco's modified Eagle's medium plus phenol red; DMEM-G, DMEM without glucose; DMEM-G+E2, DMEM plus 1 mM estrogen without glucose.

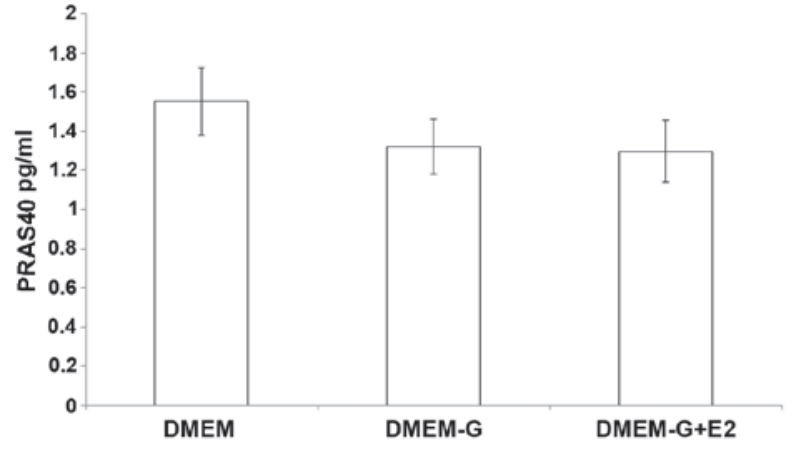

Figure 5. The effect of E2 on PRAS40 expression in N38 cells under hypoglycemic conditions after $24 \mathrm{~h}$, as determined using an enzyme-linked immunosorbent assay. No significant alterations in PRAS40 expression were observed among all treatment groups. PRAS40, proline-rich AKT substrate of $40 \mathrm{kDa}$; DMEM; Dulbecco's modified Eagle's medium plus phenol red; DMEM-G, DMEM without glucose; DMEM-G+E2, DMEM plus $1 \mathrm{mM}$ estrogen without glucose.

conditions, the number of viable cells in the DMEM-PR+E2 group decreased over the $72 \mathrm{~h}$ period, which indicated that phenol red had no additive effects on cell viability. Similar to $72 \mathrm{~h}$, no neuroprotective effects of estrogen on cell viability were observed at $96 \mathrm{~h}$.

Assessing the effects of E2 on hypoglycemia-induced cytotoxicity in N38 cells. Consistent with the MTT assay at $24 \mathrm{~h}$, an increase in the release of LDH (\% cytotoxicity) from dead cells was observed in N38 cells cultured under hypoglycemic conditions when compared with those cultured under normal conditions (Fig. 4). A significant decrease $(\mathrm{P}<0.0001)$ in LDH activity was observed in cells under hypoglycemic conditions following exposure to E2, at $24 \mathrm{~h}$ when compared with untreated cells under hypoglycemic conditions. However, the protective effects of E2 on hypoglycemic shock were reduced within $72 \mathrm{~h}$. A marked increase in LDH activity was observed between cells exposed to E2 at $24 \mathrm{~h}$ compared with cells exposed to E2 for $72 \mathrm{~h}$, whereas the level of cytotoxicity was consistent in cells cultured under normal or hypoglycemic conditions at these time points (Fig. 4). These results suggested that E2 may prolong the viability of cells under hypoglycemic conditions.
Effect of E2 on PRAS40 expression in N38 cells under hypoglycemic conditions. The AKT protein is a critical regulator of cell survival, the levels of which may be affected by E2 in the absence of glucose availability, and can be assessed by the level of PRAS40 expression. At $24 \mathrm{~h}$, no significant alterations in PRAS40 expression were observed in cells under hypoglycemic conditions following exposure to E2 when compared with untreated cells under hypoglycemic conditions. In addition, a slight decrease in PRAS40 expression was observed in cells under hypoglycemic conditions compared with those cultured under normal conditions. These results suggest that additional signaling pathways may mediate the effects of E2 under hypoglycemic conditions.

\section{Discussion}

The present study is the first, to the best of our knowledge, to report the neuroprotective effects of E2 on hypoglycemic injury in a hypothalamic cell line. The results indicated three novel observations: i) E2 exhibits neuroprotective effects, which dissipate over time; ii) a subset of neuronal cell exist that can resist hypoglycemic insult even after $72 \mathrm{~h}$; and iii) E2 may not exert the neuroprotective effects through AKT/PRAS40 signaling pathway.

In the present study, the neuronal viability and neurotoxicity analyses demonstrated that E2 exhibited neuroprotective effects in N38 cells under hypoglycemic conditions within $24 \mathrm{~h}$ of exposure. In the absence of glucose, multiple death stimuli activate different neuronal death pathways $(6,36,37)$. In the present study, the gradual reduction in neuronal cell number in the absence of glucose, correlated with the observed decrease in mitochondrial function. Mitochondrial dysfunction serves a critical role in necrotic cell death and apoptosis. The high demand for adenosine triphosphate (ATP) in neurons is dependent on ATP production by the mitochondria $(38,39)$. Damage to mitochondria leads to the disruption of ATP production and a concomitant increase in reactive oxygen species, which can lead to cell death $(38,39)$. In the current study, the observed increase in mitochondrial function in the presence of E2 under hypoglycemic conditions may have been due to the stabilization of mitochondria under $\mathrm{Ca}^{2+}$ loading, which maintains the mitochondrial membrane potential and preserves mitochondrial function (40). Whether the observed 
increase in cell death under glucopenic stress was due to mitochondrial dysfunction or activation of apoptotic pathways (or both) remains unknown. However, E2 may facilitate mitochondrial membrane stabilization and may delay the activation of cell death signaling pathways. In the present study, the attenuation in the hypoglycemia-induced reduction in cell number was only observed within $24 \mathrm{~h}$ of $\mathrm{E} 2$ exposure and gradually decreased within $72 \mathrm{~h}$, which indicated that E2 exhibits short-term neuroprotective effects. A previous study demonstrated that E2 may facilitate cell survival rather than cellular proliferation (11), and following activation of the apoptotic signaling cascade, E2 demonstrated no effect on cell viability. In the present study, a small population of cells was unexpectedly observed to survive for $>72 \mathrm{~h}$ in the absence of glucose. Previous studies have demonstrated that astrocytes present in primary hippocampal cultures possess glycogen stores that provide a buffer to alterations in glucose reserves $(41,42)$. However, the hypothalamic model used in the present study consisted of immortalized hypothalamic neurons and no supporting cells. Therefore, additional pathways that facilitate the survival of these cells during hypoglycemic shock may have been activated.

The classical signaling pathway by which E2 modulates the expression of downstream target genes, involves the binding of E2 to the nuclear ER, which subsequently activates a signaling cascade and the transcription of a number of genes (16). However, several reports have indicated that E2 exhibits antiapoptotic effects in number of cell systems (5,43-45), via non-genomic signaling pathways. A previous study demonstrated that alterations in blood glucose levels led to fluctuations in the phosphorylation states of members of the AKT pathway in the cerebral cortex and hippocampus (46). Therefore, alterations in AKT protein levels following E2 exposure under hypoglycemic conditions in the present study were investigated by assessing PRAS40 expression. Cell survival in the presence of E2 under hypoglycemic conditions, may have been due to activation of the AKT signaling pathway involving PRAS40, or the inhibition of apoptotic pathways or additional pathways by caveolin. Several studies have demonstrated that E2 activates multiple kinases in various types of brain cells within min, including ERK, AKT and the cAMP response element binding protein (47-49). In addition, it has been reported that AKT is activated in the presence of E2 in rat adrenal medulla pheochromocytoma PC12 cells, which protects neurons against $\beta$-amyloid-induced apoptosis by upregulating telomerase activity (50). Preconditioning of neuronal cells by exposure to compounds, such as growth factors, E2 and free radicles, is an effective neuroprotective strategy against stroke (51), hypothermia (52), hypoxia (53) and involves the AKT signaling pathway. In the cerebral cortex and the hippocampus, AKT-glycogen synthase kinase $3 \beta$ (GSK3 $\beta$ ) coupling is influenced by fluctuations in blood glucose concentrations (46). Therefore, the authors speculate that E2 may be able to affect cell survival by upregulating pAKT/pPRAS40, but may have a limited effect on total AKT/PRAS40 activity, since the role of AKT in signal transduction is the amplification of signals induced by RTK (54). However, an increase in pAKT levels may serve a more significant role in determining the actual physiological effects of E2, which requires further investigation.
Taking into account the biochemical and molecular results obtained in in the present and in previous studies, it is possible that one of the mechanisms by which E2 demonstrates neuroprotective effects against hypoglycemic injury may be through activation of the pAKT signaling pathway. This would lead to the phosphorylation and inactivation of the BCL2 associated agonist of cell death protein, which prevents BCL2 associated $\mathrm{X}$-mediated release of cytochrome $\mathrm{c}$ from the mitochondria, thus protecting it from mitochondrial dysfunction and cell death. In order to elucidate the precise mechanisms of action by E2, future studies should aim to confirm whether E2 activates this signaling pathway, potentially by inhibiting distinct AKT-GSK3 $\beta$ pathway members using the LY294002 PI3K inhibitor.

In conclusion, the present data indicate that E2 exhibits significant neuroprotective effects under glucopenic stress conditions in hypothalamic cells, and demonstrates that the neuroprotective efficacy of E2 is time-dependent. The precise mechanisms by which E2 mediates these neuroprotective effects remains to be explored in future studies. The present study raises the possibility of novel pharmacological interventions against hypoglycemia and the use of E2 against neuronal deficits. In addition, the results support the role of this ovarian steroid hormone in modulating the response to recurring glucodeprivation in the central nervous system, and its mechanism of action through membrane receptors.

\section{References}

1. McCall AL: Cerebral glucose metabolism in diabetes mellitus. Eur J Pharmacol 490: 147-158, 2004.

2. Mooradian AD, Chung HC and Shah GN: GLUT-1 expression in the cerebra of patients with Alzheimer's disease. Neurobiol Aging 18: 469-474, 1997.

3. Hernández-Fonseca K, Massieu L, García de la Cadena S, Guzmán C and Camacho-Arroyo I: Neuroprotective role of estradiol against neuronal death induced by glucose deprivation in cultured rat hippocampal neurons. Neuroendocrinology 96: 41-50, 2012.

4. Routh VH, Hao L, Santiago AM, Sheng Z and Zhou C: Hypothalamic glucose sensing: Making ends meet. Front Syst Neurosci 8: 236, 2014

5. Behl C, Skutella T, Lezoualc'h F, Post A, Widmann M, Newton CJ and Holsboer F: Neuroprotection against oxidative stress by estrogens: Structure-activity relationship. Mol Pharmacol 51: 535-541, 1997.

6. Belcredito S, Vegeto E, Brusadelli A, Ghisletti S, Mussi P, Ciana P and Maggi A: Estrogen neuroprotection: The involvement of the Bcl-2 binding protein BNIP2. Brain Res Brain Res Rev 37: 335-342, 2001

7. Cheng H, Isoda F and Mobbs CV: Estradiol impairs hypothalamic molecular responses to hypoglycemia. Brain Res 1280: 77-83, 2009.

8. Wise PM, Dubal DB, Wilson ME, Rau SW and Böttner M: Minireview: Neuroprotective effects of estrogen-new insights into mechanisms of action. Endocrinology 142: 969-973, 2001.

9. Singh M, Meyer EM, Millard WJ and Simpkins JW: Ovarian steroid deprivation results in a reversible learning impairment and compromised cholinergic function in female Sprague-Dawley rats. Brain Res 644: 305-312, 1994.

10. De Nicola AF, Pietranera L, Bellini MJ, Goya R, Brocca ME and Garcia-Segura LM: Protective effect of estrogens on the brain of rats with essential and endocrine hypertension. Horm Mol Biol Clin Investig 4: 549-557, 2010.

11. Sandoval DA, Ertl AC, Richardson MA, Tate DB and Davis SN: Estrogen blunts neuroendocrine and metabolic responses to hypoglycemia. Diabetes 52: 1749-1755, 2003.

12. Cardona-Gómez GP, Mendez P, DonCarlos LL, Azcoitia I and Garcia-Segura LM: Interactions of estrogens and insulin-like growth factor-I in the brain: Implications for neuroprotection. Brain Res Brain Res Rev 37: 320-334, 2001. 
13. Singh M, Dykens JA and Simpkins JW: Novel mechanisms for estrogen-induced neuroprotection. Exp Biol Med (Maywood) 231: 514-521, 2006.

14. Goodman RL: Neural systems mediating the negative feedback actions of estradiol and progesterone in the ewe. Acta Neurobiol Exp (Wars) 56: 727-741, 1996.

15. Green PS, Gridley KE and Simpkins JW: Estradiol protects against beta-amyloid (25-35)-induced toxicity in SK-N-SH human neuroblastoma cells. Neurosci Lett 218: 165-168, 1996.

16. Meda C, Vegeto E, Pollio G, Ciana P, Patrone C, Pellicciari C and Maggi A: Oestrogen prevention of neural cell death correlates with decreased expression of mRNA for the pro-apoptotic protein nip-2. J Neuroendocrinol 12: 1051-1059, 2000.

17. Gazzaley AH, Siegel SJ, Kordower JH, Mufson EJ and Morrison JH: Circuit-specific alterations of N-methyl-D-aspartate receptor subunit 1 in the dentate gyrus of aged monkeys. Proc Natl Acad Sci USA 93: 3121-3125, 1996.

18. Toran-Allerand CD: Mechanisms of estrogen action during neural development: Mediation by interactions with the neurotrophins and their receptors? J Steroid Biochem Mol Biol 56: 169-178, 1996.

19. Bishop J and Simpkins JW: Estradiol treatment increases viability of glioma and neuroblastoma cells in vitro. Mol Cell Neurosci 5: 303-308, 1994.

20. Regan RF and Guo Y: Estrogens attenuate neuronal injury due to hemoglobin, chemical hypoxia and excitatory amino acids in murine cortical cultures. Brain Res 764: 133-140, 1997.

21. Enmark E and Gustafsson JA: Oestrogen receptors-an overview. J Intern Med 246: 133-138, 1999.

22. Zhao L and Brinton RD: Estrogen receptor alpha and beta differentially regulate intracellular $\mathrm{Ca}(2+)$ dynamics leading to ERK phosphorylation and estrogen neuroprotection in hippocampal neurons. Brain Res 1172: 48-59, 2007.

23. Gu Q and Moss RL: 17 beta-Estradiol potentiates kainate-induced currents via activation of the cAMP cascade. J Neurosci 16: 3620-3629, 1996.

24. Watters JJ and Dorsa DM: Transcriptional effects of estrogen on neuronal neurotensin gene expression involve cAMP/protein kinase A-dependent signaling mechanisms. J Neurosci 18: 6672-6680, 1998.

25. Anderson GM and Barrell GK: Effects of thyroidectomy and thyroxine replacement on seasonal reproduction in the red deer hind. J Reprod Fertil 113: 239-250, 1998.

26. Razandi M,Pedram A, Greene GL and Levin ER: Cell membrane and nuclear estrogen receptors (ERs) originate from a single transcript: Studies of ERalpha and Ebeta expressed in chinese hamster ovary cells. Mol Endocrinol 13: 307-319, 1999.

27. Rameh LE and Cantley LC: The role of phosphoinositide 3-kinase lipid products in cell function. J Biol Chem 274: 8347-8350, 1999.

28. Datta SR, Brunet A and Greenberg ME: Cellular survival: A play in three Akts. Genes Dev 13: 2905-2927, 1999.

29. Buckmaster PS and Dudek FE: Neuron loss, granule cell axon reorganization, and functional changes in the dentate gyrus of epileptic kainate-treated rats. J Comp Neurol 385: 385-404, 1997.

30. Kovacina KS, Park GY, Bae SS, Guzzetta AW, Schaefer E, Birnbaum MJ and Roth RA: Identification of a proline-rich Akt substrate as a 14-3-3 binding partner. J Biol Chem 278: 10189-10194, 2003.

31. Wiza C, Nascimento EB and Ouwens DM: Role of PRAS40 in Akt and mTOR signaling in health and disease. Am J Physiol Endocrinol Metab 302: E1453-E1460, 2012.

32. Zhang J, Zhang B, Yin Z, Chen F, Liu T, Xu H, Liu Y and Zhou X: Effects of metformin on the estrogen-induced proliferation and the expression of ER in human endometrial cancer cells. Zhonghua Fu Chan Ke Za Zhi 49: 932-937, 2014 (In Chinese).

33. Welshons WV, Wolf MF, Murphy CS and Jordan VC: Estrogenic activity of phenol red. Mol Cell Endocrinol. 57: 169-178, 1988.

34. Mosmann T: Rapid colorimetric assay for cellular growth and survival: Application to proliferation and cytotoxicity assays. J Immunol Methods 65: 55-63, 1983.
35. Regan RF and Panter SS: Traumatic neuronal injury in cortical cell culture is attenuated by 21 -aminosteroids. Brain Res 682 : 144-150, 1995.

36. Ma ZQ, Santagati S, Patrone C, Pollio G, Vegeto E and Maggi A: Insulin-like growth factors activate estrogen receptor to control the growth and differentiation of the human neuroblastoma cell line SK-ER3. Mol Endocrinol 8: 910-918, 1994.

37. Gazzaley AH, Benson DL, Huntley GW and Morrison JH: Differential subcellular regulation of NMDAR1 protein and mRNA in dendrites of dentate gyrus granule cells after perforant path transection. J Neurosci 17: 2006-2017, 1996.

38. Dykens JA: Isolated cerebral and cerebellar mitochondria produce free radicals when exposed to elevated $\mathrm{CA} 2+$ and $\mathrm{Na}+$ : Implications for neurodegeneration. J Neurochem 63: 584-591, 1994.

39. Kroemer G and Reed JC: Mitochondrial control of cell death. Nat Med 6: 513-519, 2000.

40. Simpkins JW and Dykens JA: Mitochondrial mechanisms of estrogen neuroprotection. Brain Res Rev 57: 421-430, 2008.

41. Gruetter R: Glycogen: The forgotten cerebral energy store. J Neurosci Res 74: 179-183, 2003.

42. Tamrakar P and Briski KP: Estradiol regulation of hypothalamic astrocyte adenosine 5'-monophosphate-activated protein kinase activity: Role of hindbrain catecholamine signaling. Brain Res Bull 110: 47-53, 2015.

43. Vegeto E, Pollio G, Pellicciari C and Maggi A: Estrogen and progesterone induction of survival of monoblastoid cells undergoing TNF-alpha-induced apoptosis. FASEB J 13: 793-803, 1999.

44. Billig H, Furuta I and Hsueh AJ: Estrogens inhibit and androgens enhance ovarian granulosa cell apoptosis. Endocrinology 133: 2204-2212, 1993.

45. Behl C, Widmann M, Trapp T and Holsboer F: 17-beta estradiol protects neurons from oxidative stress-induced cell death in vitro. Biochem Biophys Res Commun 216: 473-482, 1995.

46. Clodfelder-Miller B, De Sarno P, Zmijewska AA, Song L and Jope RS: Physiological and pathological changes in glucose regulate brain Akt and glycogen synthase kinase-3. J Biol Chem 280: 39723-39731, 2005.

47. Lemmon MA and Schlessinger J: Cell signaling by receptor tyrosine kinases. Cell 141: 1117-1134, 2010.

48. Filardo EJ, Quinn JA, Bland KI and Frackelton AR Jr: Estrogen-induced activation of Erk-1 and Erk-2 requires the G protein-coupled receptor homolog, GPR30, and occurs via trans-activation of the epidermal growth factor receptor through release of HB-EGF. Mol Endocrinol 14: 1649-1660, 2000.

49. Lazennec G, Thomas JA and Katzenellenbogen BS: Involvement of cyclic AMP response element binding protein (CREB) and estrogen receptor phosphorylation in the synergistic activation of the estrogen receptor by estradiol and protein kinase activators. J Steroid Biochem Mol Biol 77: 193-203, 2001.

50. Du B, Ohmichi M, Takahashi K, Kawagoe J, Ohshima C, Igarashi $\mathrm{H}$, Mori-Abe A, Saitoh M, Ohta T, Ohishi A, et al: Both estrogen and raloxifene protect against beta-amyloid-induced neurotoxicity in estrogen receptor alpha-transfected PC12 cells by activation of telomerase activity via Akt cascade. J Endocrinol 183: 605-615, 2004.

51. Kato H, Araki T, Murase K and Kogure K: Induction of tolerance to ischemia: Alterations in second-messenger systems in the gerbil hippocampus. Brain Res Bull 29: 559-565, 1992.

52. Zhao H, Sapolsky RM and Steinberg GK: Phosphoinositide-3-kinase/akt survival signal pathways are implicated in neuronal survival after stroke. Mol Neurobiol 34: 249-270, 2006.

53. Gervitz LM, Nalbant D, Williams SC and Fowler JC: Adenosine-mediated activation of Akt/protein kinase $\mathrm{B}$ in the rat hippocampus in vitro and in vivo. Neurosci Lett 328: 175-179, 2002.

54. Song G, Ouyang G and Bao S: The activation of Akt/PKB signaling pathway and cell survival. J Cell Mol Med 9: 59-71, 2005. 